\title{
POLIIIICAS DE COTAS E $O$ VESTIBULAR DA UNB OU A MARCA QUE CRIA SOCIEDADES DIVIDIDAS
}

\section{Yvonne Maggie \\ Universidade Federal do Rio de Janeiro - Brasil}

O precioso artigo de Marco Chor Maio e Ricardo Ventura Santos faz um alerta para a sociedade brasileira como um todo e especialmente para os antropólogos que estão sendo chamados a exercer um poder que parecia morto, mas volta com força total. O poder de afirmar com autoridade e na posição de autoridade a "raça" dos cidadãos.

O artigo descreve o processo de implantação em 2004 da política de cotas no vestibular de uma das mais importantes universidades federais do país, a Universidade de Brasília. Os autores concentram-se na discussão do ponto que consideram mais polêmico nesse processo, que foi a instituição de uma comissão que exerce o poder de "peritagem racial" para decidir quem é "realmente" negro e quem está "fraudando". Nessa comissão, entre outros, há um representante do movimento negro e também um antropólogo.

Qual o papel da antropologia nesse processo que vem sendo implantado no país desde a Conferência de Durban Contra o Racismo a Xenofobia e Discriminações Correlatas, promovida pela ONU em 2001, e que culminou com o edital do Vestibular da UnB? O edital exige do candidato que escolha inscrever-se nas cotas raciais, que tire uma fotografia no ato da inscrição e depois passe por um exame que é feito por uma comissão. A pergunta central dos autores do texto em debate e que não cala na mente do leitor é exatamente qual a legitimidade da antropologia para intervir nesse processo e servir de fiel da balança em um processo que parecia estar morto, mas reacendeu com força total no início do século XXI. O papel de classificador de "raças", daquele que reafirma com sua autoridade quem é "cafuzo”, "mameluco”, “mulato”, “índio”, “negro” ou "branco”.

Os autores afirmam que esse processo foi mais perturbador do que os outros sistemas implantados em vestibulares de universidades públicas por ter colocado por terra o princípio e o respeito à autoclassificação racial. A 
UnB inaugurou uma nova sistemática obrigando o candidato a aceitar uma perícia sobre sua declaração e auto-identificação racial. Para Maio e Santos, o sistema implantado "operou uma ruptura com uma espécie de 'acordo tácito’ que vinha vigorando no processo de implantação do sistema de cotas no país, qual seja, o respeito à auto-atribuição de raça no plano das relações sociais. A valorização desse critério, próprio das sociedades modernas e imprescindível face à fluidez racial existente no Brasil, cai por terra a partir das normas estabelecidas pela UnB”.

Segundo Maio e Santos, essa norma da UnB, implantada para coibir os "fraudadores", acaba instituindo o que foi denominado de "tribunal racial". Essa sistemática fez aparecer, segundo os autores, a complexa relação que se estabeleceu entre os movimentos sociais, a academia e as instâncias governamentais. Os antropólogos foram chamados a exercer uma função que foi extirpada do cenário de nossa ciência, mas que preencheram desde a segunda metade do século XIX até pelo menos o final dos anos 1930, qual seja, a de classificadores de "raças".

Como eu disse mais acima, os autores acreditam que o edital da Unb rompeu de forma radical com algo que vinha sendo feito até então na implantação das ações afirmativas. No entanto, é preciso lembrar que este princípio que ficou explícito no edital da UnB já estava presente desde a primeira lei instituída no Rio de Janeiro nas universidades do Estado, e que obrigava os candidatos no formulário inicial de inscrição a declarar sob penas da lei a sua "raça": "De acordo com o decreto no 30.766, de 04/03/ 2002, declaro, sob penas da lei, identificar-me como negro ou pardo: ( ) SSim/( ) N-Não". ${ }^{1}$ Desde então, a "raça” foi finalmente entronizada no nosso país como alguns de nós vêm afirmando. ${ }^{2} \mathrm{O}$ candidato não tinha saída. Ou era negro ou não era negro. $\mathrm{O}$ edital da UnB foi mais do que o rompimento de um acordo tácito, revelou o que estava já presente desde a primeira lei instituída pela Assembléia Legislativa do Rio de Janeiro. As cotas em si implicam numa lógica que se opõe radicalmente ao nosso sistema de classificação racial dominante.

1 Ficha de inscrição do candidato ao vestibular da Uerj 2003 (grifo meu).

2 Ver Fry (2000, 2004), Maggie e Fry (2002), Maggie (2004a, 2004b), Góes (2004) e Grin (2004). 
O Brasil ao longo do século XX lutou desesperadamente para extinguir a marca que o racismo do século XIX imprimiu sobre o nosso povo. Foi o modernismo que com todas as suas imperfeições lutou pela instituição de um outro paradigma no qual a "raça" não marcava indelevelmente os indivíduos. ${ }^{3}$ Mas o processo de implantação da reserva de vagas para negros nas universidades públicas culminou com o que foi instituído na UnB, colocando a nu aquilo que antes estava como oculto no mar de boas intenções que acompanha qualquer política pública cujo objetivo é diminuir iniqüidades.

Afinal, não era esse mesmo o objetivo dessa política? Construir uma classificação racial menos "ambígua”? O que salta aos olhos de qualquer observador mais atento ao que se passa no mundo é que as cotas raciais vieram para refazer o nosso sistema de classificação racial. Como instituir cotas raciais sem antes classificar rigidamente aqueles que têm direito e os que não têm? Todos os países que implantaram essa política ou já possuíam um sistema rígido de classificação racial ou tiveram que criá-lo.

$\mathrm{O}$ artigo de Maio e Santos descreve o processo que vivemos desde a Conferência de Durban, em 2001, mas que, como demonstraram Monteiro (2003) e Costa Pinto (1998), vem de longa data ${ }^{4}$ e que culminou com a criação da comissão na qual um antropólogo participa para classificar e definir a "raça" dos proponentes. Quem são os fraudadores? São os que utilizam o sistema brasileiro de identificação racial? Quem é mais discriminado? Aquele de pais ricos que têm a pele negra ou o que tem a pele clara e os pais pobres e nem tão pretos? Para não ser fraudador, o candidato tem que se identificar com a concepção de negro como está hoje nas estatísticas que medem as desigualdades raciais? ${ }^{5}$ A Comissão da UnB teve e terá (porque ainda está em vigor) que enfrentar o que está agora instituindo no Brasil, ou seja, o processo de reclassificação racial próprio das situações sociais que entronizam a "raça" com a pretensão de combater o racismo.

3 Oracy Nogueira (1955) foi o primeiro a descrever essa característica da nossa sociedade em oposição à sociedade norte americana. Fry vem discutindo esse tema de muitos prismas desde o seu clássico Feijoada e Soul Food, relido 20 anos depois em Fry (2001).

4 Monteiro (2003) e Costa Pinto (1998).

5 Kamel (2003) vem discutindo a questão das sérias implicações de se fazer a junção estatística dos dados de pretos e pardos nas pesquisas sobre desigualdade racial no Brasil. Carvalho (2004) também discutiu essa questão, que chamou de genocídio racial estatístico.

Horizontes Antropológicos, Porto Alegre, ano 11, n. 23, p. 286-291, jan/jun 2005 
Digo que esse dilema está agora implantado no país porque, em recente pesquisa em escolas da rede pública do Estado do Rio de Janeiro, o dilema apareceu de forma muito nítida. Aplicamos um questionário para estudantes do primeiro ano do ensino médio. Era ainda um pré-teste. Entre as perguntas, havia uma que pedia aos estudantes que autoclassificassem em uma das categorias do Censo Demográfico. A pergunta, igual à formulada pelo IBGE, era a seguinte: Qual é sua cor/raça: ( ) branca ( ) preta ( ) parda ( ) amarela ( ) indígena.

Essa pergunta foi a que suscitou mais dúvidas e mais reação de todo o extenso questionário. A maioria dos estudantes não queria identificar-se em nenhuma das categorias. Alguns falaram e outros escreveram à margem da resposta fechada, raça humana. Outros riam e perguntavam aos colegas, qual a minha cor? Outros ainda falaram revoltados que essa pergunta estava errada porque não existem "raças" humanas.

No entanto, antes dessa pergunta havia outra que questionava sobre as cotas. Perguntados se já tinham ouvido falar de reserva de vagas para universidades públicas, $70 \%$ de estudantes entre 15 e 17 anos e no primeiro ano de ensino médio de uma pequena amostra de escolas da rede estadual em bairros muito diversificados do Estado do Rio de Janeiro disseram que sim. Perguntados se concordavam com as cotas para negros, 50\% responderam que sim. Perguntados ainda se concordavam com as cotas para pobres, $75 \%$ concordavam. A maioria (72\%) mostrou-se favorável a cotas para estudantes de escolas públicas. No geral, os estudantes estão mais de acordo com as cotas para pobres e para estudantes de escolas públicas, indicando que essas modalidades de reservas de vagas estão mais próximas de suas concepções de justiça distributiva. No entanto, 50\% dos alunos concordaram com as cotas para negros, apesar de muitos deles terem manifestado seu desconforto diante da pergunta que exigia a autoidentificação em uma das categorias raciais segundo o IBGE.

Depois de discutir com esses estudantes e ler o artigo do Maio e Santos, fico me perguntando: será que aqueles que estão propondo e aplicando essa política de reserva de vagas para negros estão se dando conta do que isso significa em termos da construção ou reconstrução da noção de "raça” em nosso país? Se os estudantes dizem que "raça” não existe e que pertencem à raça humana, a partir de agora, com as cotas raciais, terão que abdicar desse pressuposto lógico para concordar com a política pública implantada. Não há como fugir do dilema. Ou você é contra 
a idéia de "raça" e concorda que pertence à raça humana ou você concorda que "raças" existem. Se elas existem e algumas são mais discriminadas que outras e merecem ou fazem jus, ou como justiça, há que se criar uma política especial para elas.

Os antropólogos estão no mesmo dilema dos estudantes entrevistados nas escolas públicas. Alguns (antropólogos) já decidiram que, para fazer justiça, faz-se necessário antes recriar a "raça" e marcar os indivíduos de forma definitiva. A pergunta que os autores do texto em debate se fazem é exatamente se há reflexão sobre o que significam as cotas raciais no plano da concepção mais ampla de humanidade. Tentamos, no Brasil, ao longo do século $\mathrm{XX}$, construir uma sociedade na qual os indivíduos podiam transitar entre marcas ou até mesmo não se pensar a partir delas. O que essas políticas estão propondo é o fim dessa possibilidade e o início de uma marcação muito rígida de indivíduos, que não poderão mais dizer que, tãosomente, pertencem à raça humana. Maio e Santos fazem o alerta e, mais ainda, dizem que a moderna ciência genética respalda o que os brasileiros acreditavam e o que os estudantes dessas escolas reafirmaram. Não há "raças" humanas, mas raça humana. Sendo assim, um "tribunal” do tipo inaugurado na UnB só faz colocar a nu o que está por trás das cotas raciais, ou seja, o ideário racial que instaurou no mundo a separação e a marca que cria sociedades divididas.

\section{Referências}

CARVALHO, José Murilo de. Genocídio racial estatístico. O Globo, Rio de Janeiro, p. 7, 27 dez. 2004.

COSTA PINTO, Luiz Aguiar. O negro no Rio de Janeiro. Rio de Janeiro: Editora UFRJ, 1998.

FRY, Peter. Politics, nationality, and meanings of "race” in Brazil. Daedalus: Journal of the American Academy of Arts and Sciences, n. 129, p. 83-118, 2000.

FRY, Peter. Feijoada e Soul Food 20 anos depois. In: FRY, Peter. Fazendo antropologia no Brasil. Rio de Janeiro: DP\&A, 2001. p. 35-54.

FRY, Peter. A lógica das cotas raciais. O Globo, Rio de Janeiro, p. 7, 14 abr. 2004. 
GÓES, José Roberto Pinto de. Cotas, um remédio que é veneno. O Estado de São Paulo, São Paulo, p. 3, 13 abr. 2004.

GRIN, Monica. Você é a favor de cotas para negros? Não. Correio Brasiliense, Brasília, p. 30, 18 abr. 2004.

KAMEL, Ali. Somos todos pardos. Rio de Janeiro, O Globo, p. 7, 29 dez. 2003.

MAGGIE, Yvonne. Em breve um país dividido. O Globo, Rio de Janeiro, p. 7, 27 dez. 2004a.

MAGGIE, Yvonne. O eu e os outros: o ideário modernista em questão. 2004b. Disponível em: <http://www.Observa.ifcs.ufrj.br>. Acesso em: 2 mar. 2005.

MAGGIE, Yvonne; FRY, Peter. O debate que não houve. Enfoques Online: revista eletrônica dos alunos do PPGSA, v. 1, n. 1, dez. 2002. Disponível em: <http://www.enfoques.ifcs.ufrj.br/>. Acesso em: 2 mar. 2005.

MONTEIRO, Fabiano Dias. Retratos em branco e preto, retratos sem nenhuma cor: a experiência do Disque-Racismo da Secretaria de Segurança Pública do Estado do Rio de Janeiro. Dissertação (Mestrado em Sociologia)-Programa de Pós-Graduação em Sociologia e Antropologia do IFCS, Universidade Federal do Rio de Janeiro, Rio de Janeiro, 2003.

NOGUEIRA, Oracy. Preconceito racial de marca e preconceito racial de origem (sugestão de um quadro de referência para a interpretação do material sobre relações raciais no Brasil). In: ANAIS do XXXI Congresso Internacional dos Americanistas. São Paulo: Editora Anhembi, 1955. p. 409-434. 